"تأثير استخدام استراتيجية التعليم المتمايز علي تعلم مهاره التمرير في كرة السلة بدرس التربية الرياضية

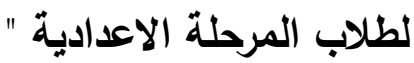

أ.م.د/ وائل السيد العبد خليفة

الباحث/ عبد خالد شعبان

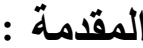

إن أستخدم طرق التعلم الحديثة في العملية التعليمية هي عملية فعاله في الوصول إلى تعلم أفضل

مع اقتصاد في الوقت والجهد والمال وخاصة عند استخدام طريقة التعلم المناسب ونوع المهارة المراد تعلمها من ناحية نوعها وخصائصها ، حيث لا توجد طريقة للتعلم فعاله مع جميع مهارات الألعاب المختلفة . أن استعمال استراتيجيات التدريس الحديثة تساعد في تحقيق نتاجات فعالة داخل الصف اذ تودي الى تحقيق تغير سلوك المتعلمين وتتمية قدراتهم على التفكير والأبداع وتعطي لكل من المعلم والمتعلم ادوار معينة

تخدم النتاجات التعليمية ـ ( • : (111)

وادراكا واستجابة لتلك التحديات والمتطلبات فقد ظهر مفهوم التعليم المتمايز والذي نال قدرا كبيرا من

الرعاية والاهتمام من قبل الأنظمة التعليمية في الدول المتقدمة ، أي ان التدريس الذي يخطط بعيدا عن قدرات وميول واتجاهات واستعدادات ورغبات وحاجات المتعلمين الفعلية لا يمكن ان يحقق اهدافه مهما كان من جودة واتقان ، وعلى العكس فمعرفة المعلم بقدرات المتعلمين وخصائصهم العقلية ومسنويات نموهم وتحصيلهم وخلفياتهم العلمية والاقتصادية والاجتماعية، وكذلك معرفة اتجاهاتهم وميولهم وقيمهم، تجعله أكثر فعالية في نواصله وتفاعله معهر ، كما تساعد المتعلمين على تكوين اتجاهات ايجابية نحو المادة الدراسبة ونحو المعلم.( ؛ :

كما يعد التعليم المتمايز هو تعليم يهدف الى رفع مستوى جميع الطلاب ، وليس فقط الطلاب الذين

يواجهون مشاكل في التحصيل ، ويعرف ايضا إنه سياسة مدرسيه تأخذ باعتبارها خصائص الفرد وخبراته السابقة وانه طريقة لتقديم بيئة تعليمية مناسبة لجميع الطلاب تهدف الى زيادة إمكانات وقدرات الطالب ، إن النقطة الأساسية في هذه السياسة هي توقعات المعلمين من الطلاب واتجاهات الطلاب نحو إمكاناتهم

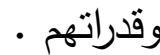

ويعد مفهوم التعليم المتمايز مع التطور الذي يمر به العالم في كافة المجالات ومع تغير نظرة الناس لكثير من الامور واختلاف طريقة تفكيرهم وتوجهاتهم عن السابق فلابد لنا كتربويين ان نقف لنفكر في هذا الجيل الجديد من الطلاب وما يمرون به من نقله كبيرة تختلف عن الماضي في كافة النواحي، فهؤلاء الطلاب 
يعيشون في زمن مختلف ، وقد تتبهت وزارة التعليم لذلك وحرصت على التطوير في المناهج لتتمانشى مع ما يمر به الطالب من ظروف بهدف تتمية عقله وتفكيره والاستفادة مما حوله من تكنولوجيا بما يعود عليه بالفائدة ، كما اهتمت بتطوير المعلم واخضاعه لدورات تدريبية تؤهله للتعامل مع هذه المناهج المطورة ،

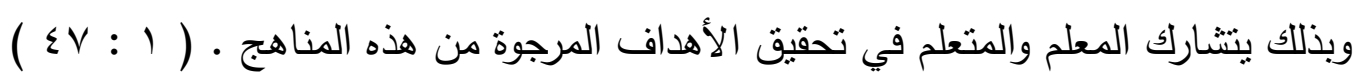

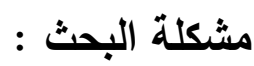

أن التعليم ينأثر إلى حد كبير بأساليب التدريس التي يتبعها المعلم ، لذا فأن التعليم الذى يقوم على

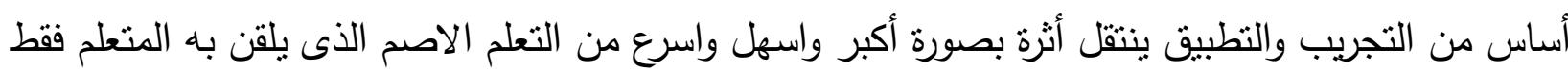
، وقد ظهرت اساليب جديدة في التدريس تساعد على نقل العملية التعليمية من المادة الدراسية إلى المتعلم وبذلك أصبحت المادة وسيلة وليست هدفا ، والتربية الرياضية بطبيعتها تتاسب هذا النوع من التعلم ، لهذا كان على المعلم مسئولية كبيرة في تزويد المتعلمين بما يمكنهم من الاستعداد للتعامل مع متغيرات المستقبل

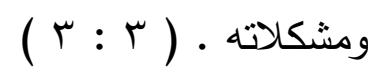

ويشير مجدى عزيز إبراهيم ( ع . . r ) أن استراتيجية التعليم المتمايز من الاستراتيجيات التعليمية الحديثة التي توفر فرص تعليمية مناسبة لكل التلاميذ حيث يتم تعليم المهارة بها بأكثر من اسلوب ، وتعتمد استراتيجية التعليم المتمايز على مراعاة الفروق الفردية واستخدام أكثر من اسلوب تعليمي لتعليم مسابقة واحدة حيث يختار كل تلميذ الاسلوب الذى يتتاسب مع قدراته وإمكاناته وميولة ورغباته مما يتيح فرص ملائمة

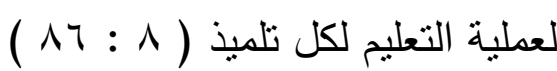

إن الفلسفة التي يقوم عليها التعليم المتمايز هي وجوب النظر إلى الطلاب على أنهم أفراد يختلفون فيما بينهم، وأن هذه الاختلافات لها من الأهمية ما يستدعي الاستجابة لها ليس عند ظهورها في الحصة ، وإنما تكون أساسا عند التخطبط للاروس.

أخيرا ، نجد أن التعليم باستخدام استراتيجية التدريس المتمايز هو استجابة منطقية لمواجهة تمايز الطلاب في الفصل الواحد ، ليناسب اختلافهم ، ومحاولة تقديم حل لرفع المستوى التعليمي بشكل عام لجميع

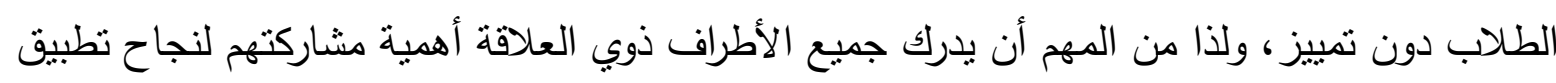

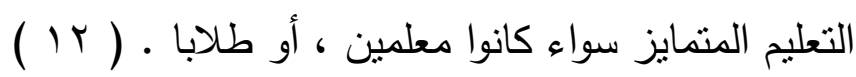


ومما سبق يرى الباحث أن الاساليب المستخدمة في تدريس المهارات الرياضية في المنهاج المقرر لطلاب

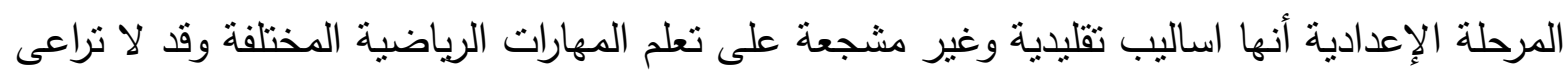
الفروق الفردية بين التناميذ ، ومن هذا المنطلق ولمواكبة النطور الكبير الذى حدث في طرق واساليب التدريس باختيار ما يتتاسب منها مع زيادة اعداد الطلاب وضيق وقت الوحدة التعليمية مما يخفف العبء على المعلم ويتيح للمتعلمين فرصة الاثتراك الإيجابي في العملية التعليمية جاءت فكرة البحث حول محاولة التعرف على نأثير استخدام التعليم المتمايز علي تعلم بعض مهارات التمرير في كره السلة بدرس التربية

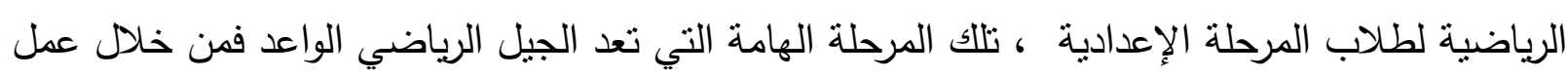
الباحث كمدرس للتربية الرياضية داخل مدرسة زهراء الاندلس الإعدادية بمحافظة الفيوم ، وكان هذا هو الدافع الذي أدي الباحث إلى إجراء هذه الدراسة للتعرف تأثثر استخدام التعليم المتمايز علي بعض مهارات التمرير في كره السلة بدرس التربية الرياضية لطلاب المرحلة الإعدادية

هاف البحث :

1- التعرف على تأثير استحدام استراتيجية التعليم المتمايز على تعلم مهاره التمرير في كرة السلة بدرس

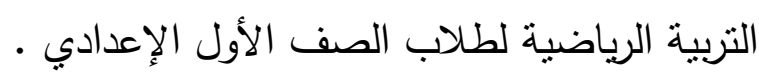

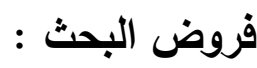

1 - توجد فروق دالة إحصائياً بين متوسط درجات القياس القبلي والبعدي للمجموعة التجريبية في مستوى

التحصيل المهارى لصالح القياس البعدي •

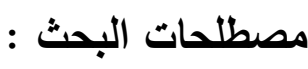

التعليم المتمايز : احتباجات المتعلمين المختلفة، ومعلوماتهم السابقة واستعداداتهم للتعلم ، ومستواهم اللغوي ،

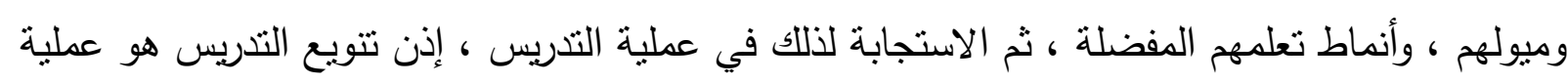

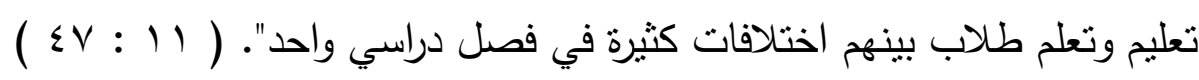

اجراءات البحث: 
تحقيقا لأهداف البحث وفروضه استخدم الباحث المنهج التجريبي نظرا لملائكته لطبيعة البحث باستخدام التصميم التجريبي لمجموعه تجريبيه واحده مجتمع البحث : n

اشتمل مجتمع البحث على طلاب الصف الاول الاعدادي بمدرسه زهراء الاندلس الخاصة بمحافظه الفيوم ، التابعة لا داره الفيوم ، والبالغ قوام التلاميذ ( • ع) تلميذ ، وذلك في الفصل الدراسي الأول للعام الدراسي $\cdot r \cdot 19 / r \cdot 11$ عينة البحث:

تم اختبار العينة بالطريقة العمدية من طلاب الصف الاول الاعدادي بمدرسه زهراء الاندلس والتابعة لإدارة

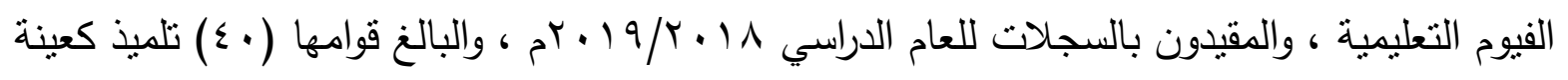
اساسية

جدول (1)

توصيف عينة البحث

\begin{tabular}{|c|c|c|c|c|c|}
\hline النسبة & الإجمالي & طلاب باقون للإعادة & طلاب من الخارج & طلاب مستجدون & م \\
\hline$\% 1$. & $\varepsilon$. & - & - & $\varepsilon$. & مجتمع الدراسة \\
\hline$\% r v, 0$ & 10 & - & - & 10 & المجموعة الاستطلاعية \\
\hline$\% 0$ & $r \cdot$ & - & - & r. & المجموعة التجريبية \\
\hline$\% \backslash r, 0$ & 0 & - & - & 0 & طلاب لم يخضعوا للتجربة \\
\hline
\end{tabular}

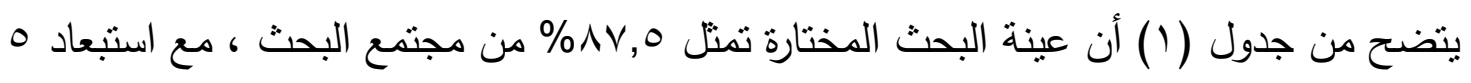

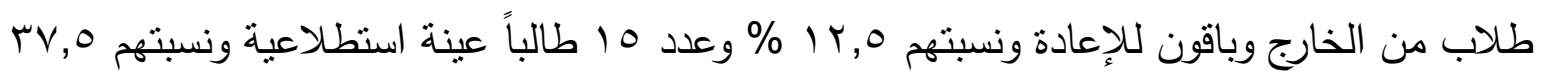
\% وذللك لإجراء المعاملات العلمية للاختبارات المهارية المستخدمة في البحث

وقد قام الباحث بإيجاد التجانس بين مجموعتي البحث في بعض المتغيرات التي لها علاقة بنتائج البحث وهى بعض معدلات النمو ( السن - الطول - الوزن ) وجدول ( r) يوضح تجانس العينة

جدول (r)

توصيف عينة البحث: 


\begin{tabular}{|c|c|c|c|c|c|c|}
\hline معامل & المعياري & |الوسيط & الحستوسط & وحدة القياس & المتغيرات & م \\
\hline $0.681-$ & 0.489 & 12.000 & 11.650 & سنة & العمر & 1 \\
\hline 0.736 & 1.809 & 151.000 & 151.700 & سم & الطول & r \\
\hline 0.743 & 0.940 & 49.000 & 49.400 & كجم & الوزن & $r$ \\
\hline
\end{tabular}

تتثير نتائج الجدول إلى المتوسط الحسابي والانحراف المعياري والوسيط ومعامل الالتواء لمتغيرات

السن ، والطول ، والوزن ، كما يتضح من الجدول اعتدالية توزيع أفراد العينة في متغيرات النمو حيث تراوح

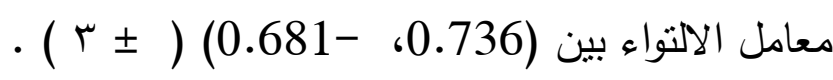
جدول (r)

توصيف عينة البحث في المتغيرات المهارية قيد البحث في القياس القبلي

\section{$r \cdot=\dot{0}$}

\begin{tabular}{|c|c|c|c|c|c|c|}
\hline الالتواء & الانحراف & الوسيط & الحستوسط & وحدة & المتغيرات & p \\
\hline 0.401 & 0.681 & 4.000 & 4.400 & الارجة & التمرير سرعة ودقة & \\
\hline
\end{tabular}

تتشير نتائج الجدول إلى المتوسط الحسابي والانحراف المعياري والوسيط ومعامل الالتواء للمتغير سرعه ودقه التها التمرير قبد البحث ، كما يتضح من الجدول اعتدالية نوزيع أفراد العينة في المتغير المهارى سرعاه ودقيه كما لتصرير قيد البحث

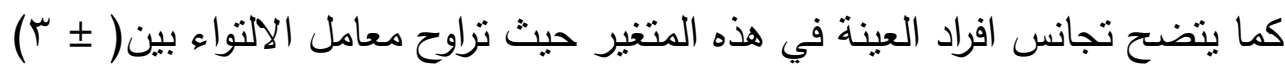

$$
\text { جدول (s ) }
$$

دلالة الفروق بين القياس القبلي والقياس البعدي في

الاختبارات المهارية قيد البحث

\begin{tabular}{|c|c|c|c|c|c|c|}
\hline احتمال الخطأ & قيمة "ن" & مجموع الرتب & متوسط الرتب & 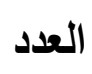 & الاتجاه & الاختبار \\
\hline \multirow{2}{*}{0.000} & \multirow{2}{*}{ "4.005 } & 0.00 & 0.00 & 0 & - & \multirow{2}{*}{ اختبار سرعة ودقة التمرير } \\
\hline & & 210.00 & 10.50 & 20 & + & \\
\hline
\end{tabular}




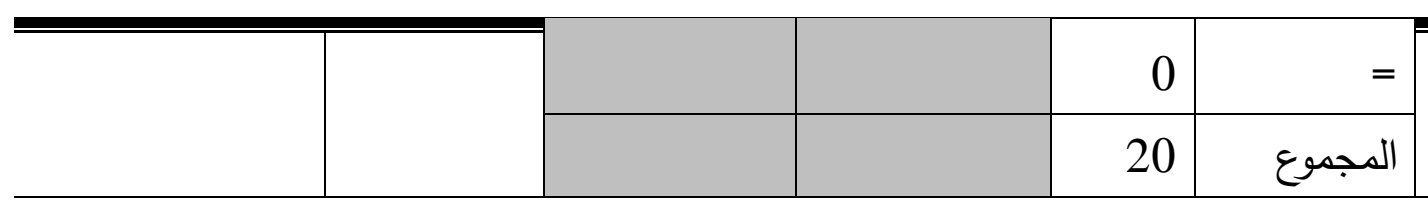

"قيمة " ذ " الجدولية عند مستوى معنوية ه م. . . هي 97 . 1 هي

تشير نتائج جدول (ع) إلى أنه توجد فروق ذات دلاله إحصائية بين القياس القبلي والقياس البعدي

ولصالح القياس البعدي في الاختبار المهارى سرعه ودقه التمرير قبد البحث .

يتضح من جدول(\&) وجود فروق دالة إحصائياً عند مستوى (0 . . •)بين القياسات القبلية والبعدية

للمجموعة التجريبية في المتغير المهارى سرعه ودقه التمرير "قيد البحث" ولصالح القياسات البعدية. وسائل وأدوات جمع البيانات :

قام الباحث بالاطلاع على المراجع والدراسات السابقة المشابهة بغرض الاستفادة منها في كيفية تصميم استمارة استطلاع أراء السادة الخبراء، وكذلك تحديد وإجراء الاختبار المهارى" قيد البحث". - استمارة استطلاع آراء الخبراء -

ا - استمارة تسجيل البيانات الخاصة بالاختبارات" قيد البحث". "إعداد الباحث" مرفق () r- استمارة استطلاع أراء السادة الخبراء حول أهم الاختبارات المهارية للمهارات الاساسية " قبد البحث".

مرفق () مرن

- الأدوات والأجهزة المستخدمة في البحث : - الأجهزة المستخدمة في البحث : 1 - جهاز الرستاميتز لقياس الطول .

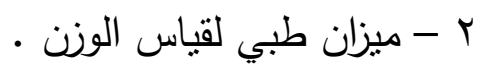

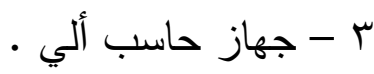

ـ - أقراص ممغنطة عليها البرنامج المعد من قبل الباحث .

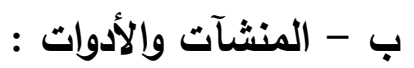
ملعب كرة سلة - غرفة تغيير ملابس - كور سلة .

القياسات :

أ : القياسات القبلية عن طريق درجات التكافؤ :

للتعرف على مستوى الطلاب في المجموعة التجريبية قبل البدء في تتفيذ البرنامج تم إجراء القياسات القبلية الخاصة بمستوى الأداء المهارى على عينة البحث ابتداء من يوم ........................ عن طريق ئق لجنة من المحكمين في مجال كرة السلة المكونة من السادة الأساتذة بقسم مناهج وطرق التدربس وقسم التذريب الرياضي بكلية التربية الرياضية للبنين - جامعة حلوان والبالغ عددهم ( 1 ( ) محكمين في مجال 
كرة السلة مرفق () وبذلك لم يتدخل الباحث في عملية التقويم الخاصة بالأداء المهارى لمهارات كرة السلة

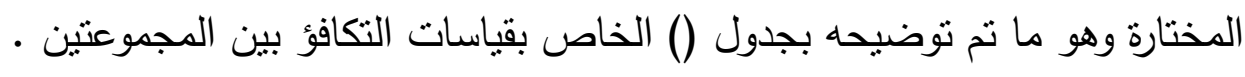
وذلك باستخدام حزمة البرامج الإحصائية ونSS. وبرنامج ميكروسوفت أكسل

\section{الأجهزة المستخدمة في البحث :}

جهاز الرستاميتز لقياس الطول مقدرا بالسنتيمتر - شريط قياس مرن (بالسنتيمتر) - ميزان طبي لقياس الوزن (بالكيلو جرام) - ساعة إيقاف لحساب الزمن - كرات طبية - جهاز الديناموميتر. وقد تم التأكد من صلاحية هذه الأجهزة من خلال الدراسة الاستطلاعية كما تم معايرة بعضها بأخذ

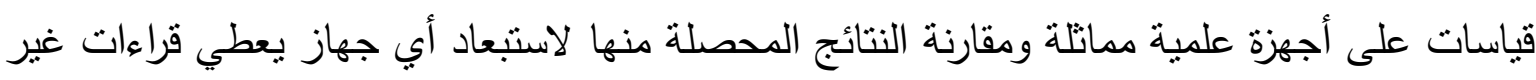
مطابقة للمعايرة .

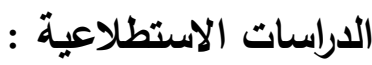

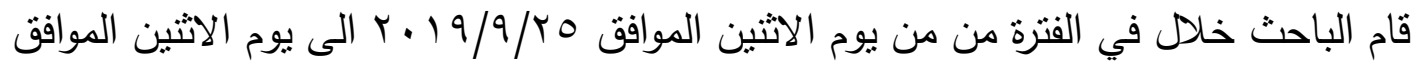

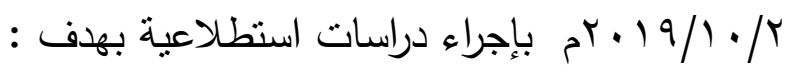
- حساب المعاملات العلمية ( الصدق - الثبات ) للاختبارات المهارية" قيد البحث" . وقد تم إجراء الدراسة الاسنطلاعية على عينة قوامها (10) تلميذ من مجتمع البحث، المعاملات العلمية للاختبارات المهارية:

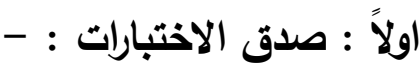
استخدم الباحث نوعان لحساب الصدق كالتالي:ج/ صدق المحكمين ( المحتوى ) : تحقق الباحث من صدق الاختبارات المستخدمة عن طريق :

عرض استمارة استطلاع رأي تحتوي على جميع الاختبارات السابقة قبل استخدامها بهذا البحث على الخبراء لتحديد مدى صدقها في قياس ما وضعت من أجله مرفق (1) وقد اتفقوا أنها مناسبة بنسبة (.9\%) للاختبارات المهارية "قيد البحث".

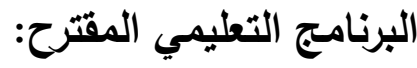

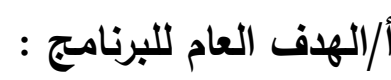

يهدف البرنامج إلى التعرف على تأثثر استخدام استراتيجية التعليم المتمايز علي تعلم مهارة التمرير في كرة السلة بدرس التربية الرياضية لطلاب المرحلة الإعدادية 
- - - أن يتاسب المحتوي مع هدف البرنامج الذي وضعه من أجله. - - مراعاة تذرج البرنامج من السهل إلى الصعب ومن البسيط إلى المركب. - - - أن يقوم البرنامج على اهتمامات الطلاب وحاجاتهم وميولهم في هذه المرحلة.

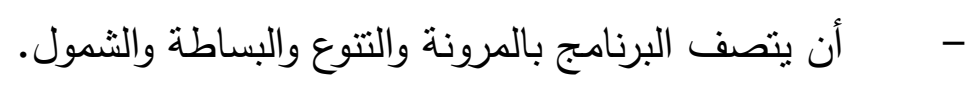

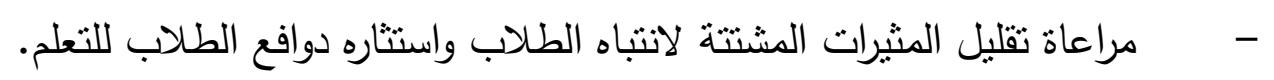
- - مراعاة الزمن الدناسب لتنفيذ البرنامج حتى يكون أكثر تأثيرا وإيجابية. - مراعاة البساطة والنتوع والثمول لا شباع رغبات المتعلم الحركية. - مراعاة خصائص النمو الحركي ومتطلباته، وعوامل الامن والسلامة. - - مراعاة إثباع حاجات الطلاب من الحركة والنشاط والثفاعلية. - - مراعاة توفير المكان المناسب والإمكانيات اللازمة لتنفيذ البرنامج. ج/ محتوي البرنامج:

تم تحديد مهارة التمرير المراد تعلمها والكقررة على تلاميذ الصف الاول بالمرحلة الإعدادية برس التربية

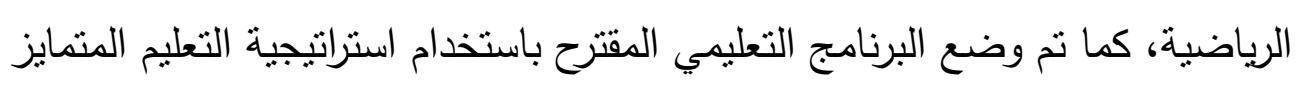

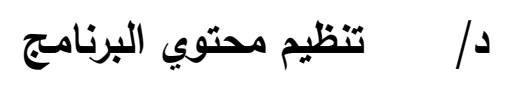
في ضوء خصائص البرنامج التعليمي المقترح باستخدام استراتيجية التعليم المتمايز قام الباحث بتحديد محتوي البرنامج في جزئيين رئيسين

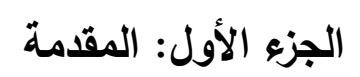

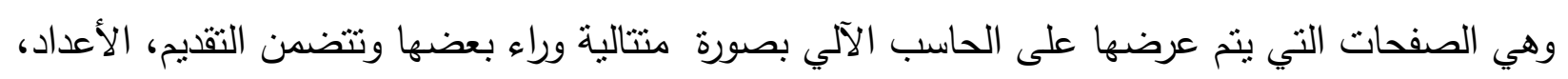

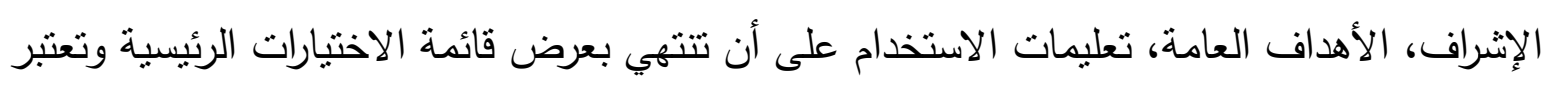
النقطة الفاصلة بين الجزء الأول والجزء الثاني. الجزء الثاني: المحتوي التعليمي: ويضضن المحتوي التعليمي المهارة الحركية الأساسية قيد البحث (مهاره التمريرة )

ويتكون المحتوي التطليمي لكل مهارة من الآتي: - - معريف ومقدمه عن المهارة. - - - مريقة أداء المهارة. 
بعض النقاط التي يجب التركيز عليها.

ت تدريبات متدرجة على المهارة.

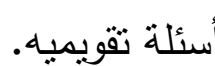

على أن يقوم الباحث بتحديد الجزء التعليمي المراد تعلمه حسب تسلسله بالبرنامج. هـ

تضمن البرنامج نوعان من الأنشطة التعليمية نوع يقوم بها المعلم والأخر يقوم به التلميذ بغيه تحقيق أهدافه وهما:

\section{أنشطة يقوم بها المعلم: - n}

قبل البدء في تدريس البرنامج:

يقوم بالتأكيد على مدى قدرة الطلاب على اداء بعد المهارات الاساسية " قيد البحث" والوقوف على الوضح الحالي لمتطلبات الاداء.

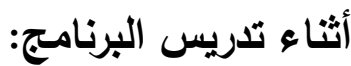

يتمثل في شرحة لمحتوي البرنامج التعليمي المقترح باستخدام استراتيجية التعليم المتمايز واستغلال إمكانيه استعراض ما به من وصور تعليمية نوضيحيه بالإضافة إلى توجيه الطلاب نحو القيام بالأنشطة التعليمية ومتابعة تقديمه وتصحيح أخطائهم التعليمية والإجابة على التساؤلات التي قد تظهر أثناء التعليم.

بعد الانتهاء من تدريس البرنامج:

- تتحدد في تكليف الطلاب بأداء النشاط المطلوب منهم والذي يتمنل في الخطوات التعليمية المتدرجة. - الأنشطة التي يقوم بها الطالب باستخدام استراتيجية التعليم المتمايز تحت إنشراف المعلم. - ينتقل من مرحلة تعليمية لأخر طبقا لسرعته الخاصة وقدراته وإمكانياته. - يمارس المهارات قبد البحث تطبيقا. و/ الإطار العام لتنفيذ البرنامج :

قام الباحث بوضع الوحدات التعليمية لبعض المهارات الحركية الاساسية في كرة السلة قيد البحث وذللك بالرجوع إلى المراجع النظرية والخبراء مصحوبة بأهداف سلوكية وقسمت إلى (^) وحدات تعليمية بواقع درس واحد أسبوعياً وفقاً للجدل الدراسي والزمن المخصص لكل وحدة تعليمية ، وبزمن (0؛ دقيقة ، وبناء على ذلك فقد استغرق تتفيذ الوحدات التعليمية (^) أسابيع وكان الثكل النهائي للوحدة التعليمية على النحو

التالي : مرفق (1) - n (1) 
الأعمال الإدارية (r دقيقة)

إحماء عام (0 دقائق)

إحماء خاص (0 دقائق)

البرنامج التعليمي (الوحدة التعليمية) (ب دقيقة)

الختام (r دقائق)

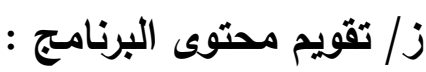

من أجل تقويم فاعلية محتوى البرنامج قام الباحث باستخدام الاختبارات المهارية والخاصة ببعض مهارات كرة السلة والتي تقيس مسنوى الطلاب في اداء بعض مهارات كرة السلة "قيد البحث". ح/ تجريب البرنامج التعليمي : بعد الانتهاء من مرحلة التصميم وتحديد مكونات البرنامج التعليمي المقترح قام الباحث بتجريب البرنامج على عينة ممانلة لمجتمع البحث ومن خارج عينة البحث الاساسية والبالغ قوامها (0 (1) طلاب وذلك خلال في

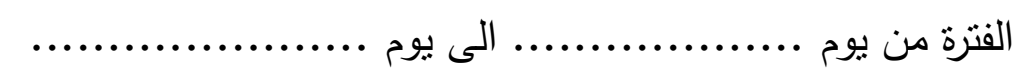

التأكد من معايير المادة التعليمية (المهارات) التي سوف تقدم للطلاب عينة البحث لمعرفة مدى فهم الطلاب للبرنامج المقترح ، وبناء على نتائج مرحلة التجريب تم إجراء التعديلات وذللك بحذف التمرينات الصعبة

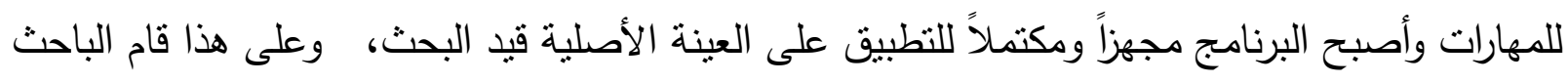
بالتنفيذ الفعلي للبرنامج التعليمي المقترح •

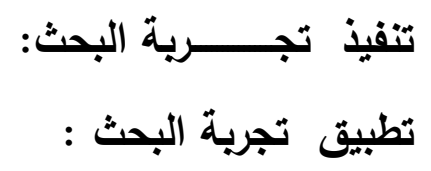

بعد إجراء الدراسات الاستطلاعية و ما أسفرت عنه قام الباحث باستكمال أوجه القصور التي لاحظها

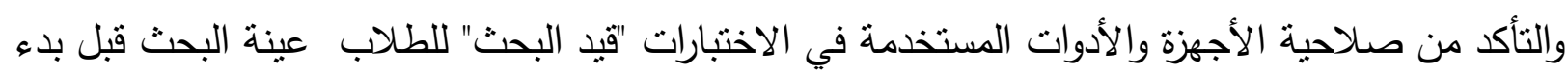
تتفيذ قياسات البحث على المجوعة التجريبية ة حيث تمت الإجراءات كما يلي :

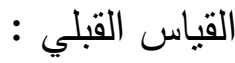

قام الباحث بإجراء القياس القبلي للمجموعة التجريبية في الاختبارات المهارية في كرة السلة " قبد البحث" وذللك خلال الفترة من يوم ............................................ على عينة البحث 
قام الباحث بتطبيق استراتيجية التعليم الهتمايز (البرنامج التعليمي المقترح) لتعلم بعض مهارات التمرير في كرة السلة " قبد البحث" لطلاب المجموعة التجرييية في القياس البعدي بينما اتبعت المجموعة التجريبية في القياس القبلي الطريقة التقليدية ( الثرح- العرض ) في التدريس وذلك عقب القياس القبلي وفي خلال الفترة من يوم ................... الى يوم . بواقع وحدة تعليمية أسبوعياً، وبزمن (0؛ د دقيقة لكل وحدة تعليمية ، بناء على ذللك استغرق تتفيذ التجربة • (^)

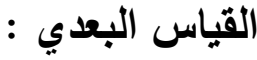

بعد انتهاء الفترة المحدة لتنفيذ البرنامج التعليمي المقترح تم إجراء القياسات البعدية على مجموعه البحث التجريبية في الاختبار المهارى " قيد البحث" وذلك خلال الفترة من يوم ..................... يوم

وقد تم القياس للاختبار المهارى على نحو ما نم إجراؤه في القياس القبلي •

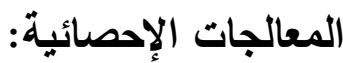

استخدم الباحث المعالجات الإحصائية للبيانات الأساسية داخل هذا البحث باستخدام برنامج الحزمة

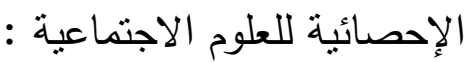
- ( SPSS) Statistical Package for Social Science

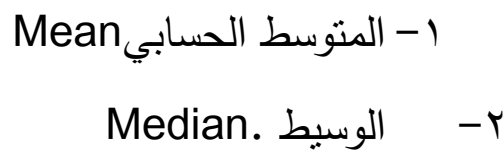
ب- ب الانحراف المعياري.Standard Deviation Skewness. - معامل الالتواء

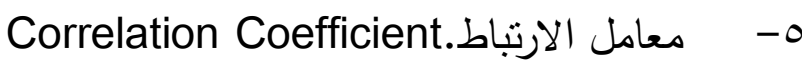

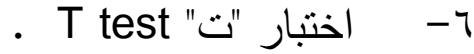
Change Ratio معامل التغيير ( التحسن ) - - م عزض ومناقشة وتفسير النتائج:

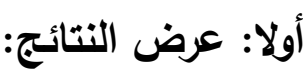

في ضوء أهداف و وفروض البحث، وفى اطار المعالجة الإحصائية سيتم عرض نتائج البحث بالترتيب 
1-عرض نتائج الفرضية الاولى من فروض البحث والذي ينص على وجود فروق ذات دلالة

إحصائية بين منوسطات القياسات القبلية والبعدية للمجموعة التجريبية علي المتغيرات المهارية لبعض مهارات كرة السلة " قيد البحث" ، لصالح القياس البعدي .

جدول() دلالة الفروق بين القياسات القبلية والبعدية للمجموعة التجريبية في المتغيرات المهارية "قبد البحث" لبعل

- توصيف عينة البحث في القياس القبلي :

جدول (0)

توصيف عينة البحث في المتغيرات المهارية قيد البحث في القياس القبلي

$r \cdot=\dot{U}$

\begin{tabular}{r|r|r|r|r|r}
\hline \hline & \\
\hline \\
0.401
\end{tabular}

تتشير نتائج الجدول إلى المتوسط الحسابي والانحراف المعياري والوسيط ومعامل الالتواء للمتغير المهارى قيد البحث ، كما يتضح من الجدول اعتدالية توزيع أفراد العينة في المتغير المهارية قيد البحث في

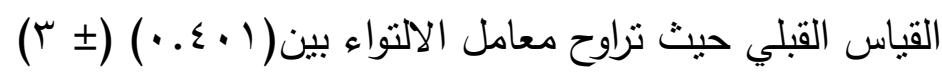

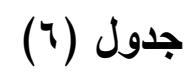

المتوسط الحسابي والانحراف المعياري للاختبارات المهارية قيد

$$
\text { البحث في القياس القبلي والقياس البعدي لإنياري }
$$

$r_{\cdot}=\dot{ }$

\begin{tabular}{|c|c|c|c|c|c|}
\hline \multicolumn{2}{|c|}{ القياس البعدي } & \multicolumn{2}{|c|}{ | القياس القبلي } & \multirow{2}{*}{ وحدة } & \multirow[b]{2}{*}{ الاختبار } \\
\hline المعياري & الحستوسط & الانحراف & الحسابي & & \\
\hline 0.571 & 8.300 & 0.681 & 4.400 & الدارجة & اختبار سرعة ودقة التمرير \\
\hline
\end{tabular}


دلالة الفروق بين القياس القبلي والقياس البعدي في الاختبارات المهارية قيد البحث

\begin{tabular}{|c|c|c|c|c|c|c|}
\hline احتمال الخطأ & قيمة "ذ" & مجموع الرتب & متوسط الرتب & 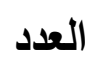 & الاتجاه & الاختبار \\
\hline \multirow{6}{*}{0.000} & \multirow{6}{*}{4.005} & 0.00 & 0.00 & 0 & - & \multirow{6}{*}{ اختبار سرعة ودقة التمرير } \\
\hline & & 210.00 & 10.50 & 20 & + & \\
\hline & & & & 0 & $=$ & \\
\hline & & & & 20 & المجموع & \\
\hline & & & & 0 & $=$ & \\
\hline & & & & 20 & المجموع & \\
\hline
\end{tabular}

"قيمة " ذ " الجدولية عند مستوى معنوية ه. .. هي 1.97

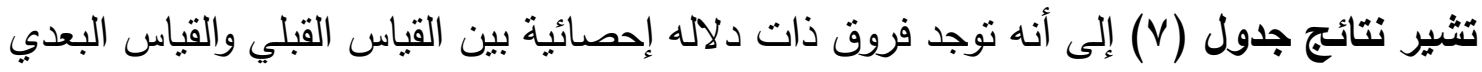

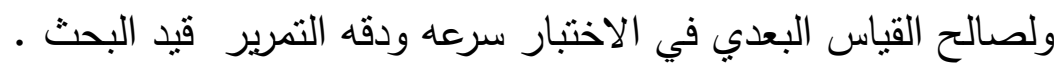

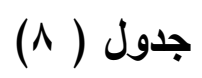

معدلات التغير للاختبار المهارى قيد البحث

$r_{\cdot}=\dot{0}$

\begin{tabular}{|c|c|c|c|}
\hline \multirow{2}{*}{ معدل التغير } & المتوسط الحسابي & المتوسط الحسابي & \multirow{2}{*}{ الاختبار } \\
\hline & القياس البعدي & القياس القبلي & \\
\hline 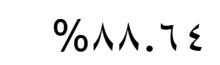 & 8.300 & 4.400 & اختبار سرعة ودقة التمرير \\
\hline
\end{tabular}

تثير نتائج جدول (^) إلي معدلات تغير القياس البعدي عن القياس القبلي للاختبار المهارى قيد

البحث. كما تراوحت نسب التغير ما بين (ـ 7.1\%\%) ولصالح القياسات البعدية للمجموعة التجريبية.

ثانيا : مناقشه تفسير نتائج البحث

يتضح من جدول(^) وجود فروق دالة إحصائياً عند مستوى (ه . . ) بين القباسات القبلية والبعدية "قبد

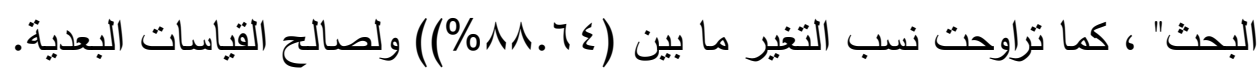

ويشير ذلك الي ان هناك فروق ذات دلالة احصائية بين القياسين القبلي والبعدي في المتغير المهارى لصالح القياس البعدي للمجموعة التجريبية. 
ويعزز البحث سبب تقدم طلاب المجموعة التجريبية الي استخدام استراتيجية التعليم المتمايز التي كان يعتمد علي مجموعة العمل التعاونية ويجعل الطلاب في حالة نشطة اثنا تعلم المهارات الأساسية بكرة السلة سرعة ودقة التمرير ـ هذا بالإضافة الي توفير تغذية راجعة للمهارة التي تم تعلمها من قبل حيث تم ذلك بصورة نشطة وموجهة من خلال الطلاب حيث ان مراحل استراتيجية التعليم المتمايز علت علي اثارة الطلاب لتعلم مهارات كرة السلة حيث ان نموذج استراتيجية التعليم المتمايز ساعد الطلاب علي اكتثاف الحلول بطريقة بنائية من خلال العمل في مجموعات صغيرة والتفاوض فيما بينهم حيث كان الطلاب محور

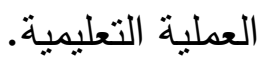

ويؤكد الباحث ان استراتيجية التعليم المتمايز عملت علي اثارة دوافع الطلاب نحو التعلم بشكل ايجابي كما انهم تساعدهم علي التفكير العلمي المنظم وجعلتهم يسيرو في العملية التعليمية وفقا لقدراتهم وسرعتهم مما تجعلهم يشعروا بذاتهم ودرورهم الفعال في تلك العملية وهذا ادي الي استبعابهم وادراكهم بشكل ايجابي لكل جزء من اجزاء الاداء المهارى وبالتالي ادي استخدام استراتيجية التعليم المتمايز بأوراقها العمل وادواتها التكنولوجية سواء لاب توب او هواتف محمولة لعرض بعض الصور عليها والبحث والاستقصاء من خلال الهواتف المزودة بالأنترنت الي زيادة دافعية الطلاب نحو اداء المهارات بالإضافة الي اعجابهم وابهارهم بهذا

النموذج التعليمي البنائي الغير تقليدي والذي ساهم بشكل ايجابي نحو التعلم من منطلق انهم وجدو ما با لهاء يتتاسب مع قدراتهم وحاولوا الارتقاء بهذه القدرات حتي يصلو الي المستوي المطلوب في الاداء المهارى لمهاره

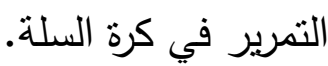

ويري الباحث ان نتيجة انتشار التكنولوجيا اتاح للطلاب القدرة علي التصفح والتجول علي الانترنت لأجراء عملية البحث والاستقصاء عن المعلومات والمعارف فلابد البعد عن الطريقة التقليدية عن توصيل المعارف والمعلومات للطلاب والاهتمام بعقول طلابنا وتتجيعهم علي البحث والاستقصاء وذللك لبناء المعارف لديهم والاحساس بقيمة ذاتهم حيث انهم هم محور التعليمية وهذاما تؤكد عملية استراتيجية التعليم المتمايز

وبذلك يتحقق صحة الفرض الثاني للبحث الذي ينص علي وجود فروق ذات دلالة احصائية بين

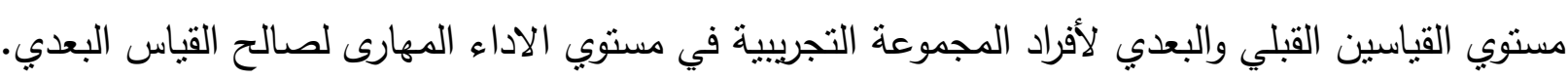

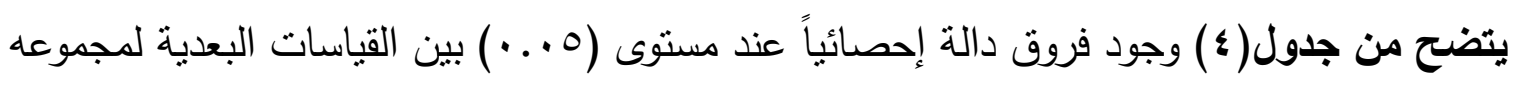
البحث التجريبية في المتغيرات المهارية "قيد البحث" ولصالح المجموعة التجريبية. 
ويعزز الباحث هذا التقام الذي طرا علي مجموعة البحث التجريبية نتيجة استخدام التعليم المتمايز

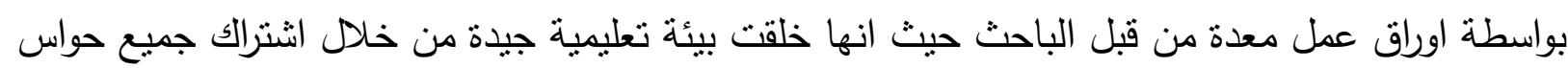
طلبة المرحة الاعدادية وأثارة دوافعهم التعليمية نحو اكتساب المهارات. ويوضح الباحث سبب تقدم وارتفاع معدلات التغيير ( نسبة التحسن) للمجموعة التجريبية في القياسات البعدية في مستوي الاداء المهارى الي استخدام استراتيجية التعليم المتمايز بشكل ايجابي الذي اتاح الفرصة

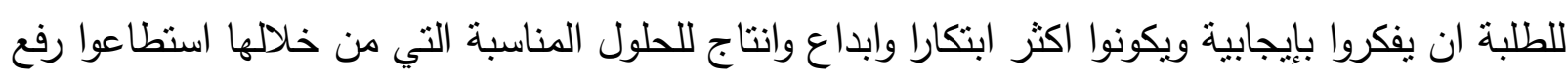
مسنوي الاداء المهارى في كرة السلة. كما يؤكد الباحث ان استراتيجية التعليم المتمايز قد ساهمت في جذب انتباه الطلاب نحوه مما جعل العملية التعليمية اكثر اثارة وتثويقا وجاذبية للطلبة نتيجة استتارة تفكيرهم بشكل ايجابي بالإضافة انه ساعد الطلبة علي العمل في ترابط بينهم وسمح بالمناقثة والحوار والتساؤل مما جعل لديهم الرغبة في التعلم بالإضافة الي تنظيم افكارهم بصورة منسلسلة للوصول الي حلول لتلاك الاسئلة المطروحة في اوراق العمل

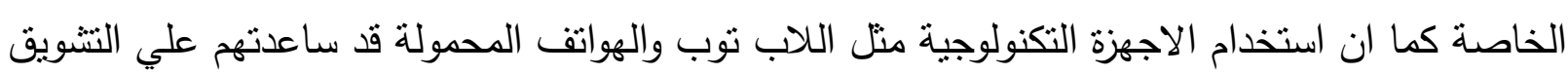
والدافعية وكل ذللك انعكس علي تقدم مستوي الاداء المهارى لديهم. الاستنتاجات والتوصيات

اولا :الاستنتاجات

الاستنتاجات:

من واقع البيانات والمعلومات التي توصل إليها الباحث وفي حدود عينة البحث وخصائصها وطبيعة وأهداف هذه الدراسة وفي حدود المجال الذي طبقت فيه وفي ضوء المعالجات الإحصائية ومن خلال مناقتشة

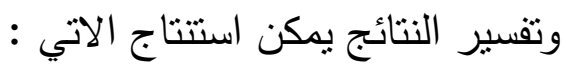
ا ـ استخدام الطرق المتبعة ( الثرح اللفظي وأداء النموذج ) كان له تأثثر إيجابي بسيط في تعلم بعض

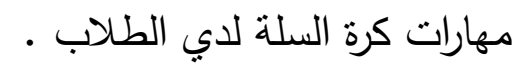

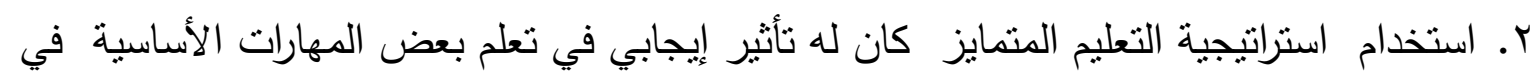

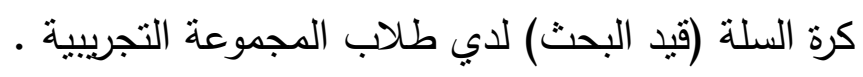

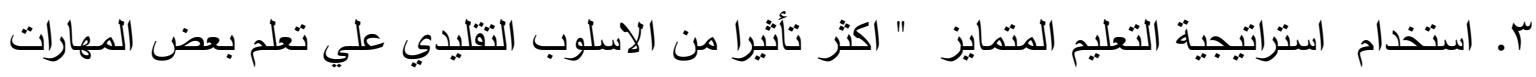
الأساسية في كره السلة (قيد البحث ) لدي المجموعة النجئة التجريبية 
في ضوء ما توصل اليه الباحث وفي ضوء مناقثة النتائج يوصي الباحث ما يلي: 1-استخدام استراتيجية التعليم المتمايز في تدريس كرة السلة في درس التربية الرياضية للمرحلة الإعدادية. r- عقد العديد من الدورات التدريية التي تعني بتدريب المعلمين علي استخدام استراتيجية التعليم المتمايز في تدريس مقررات التربية الرياضية.

ب- تدريب المعلمين علي استخدام استراتيجيات التعليم المتمايز في تدريس منهج التربية الرياضية لطلاب المرحلة الإعدادية.

ع-يوصي الباحث بإجراء مزيد من الدراسات والأبحاث تتتاول استخدام استراتيجية التعليم المتمايز في أنشطة

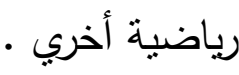

ه-يوصي الباحث بضرورة إجراء المزيد من الدراسات والأبحاث علي مراحل سنية مختلفة.

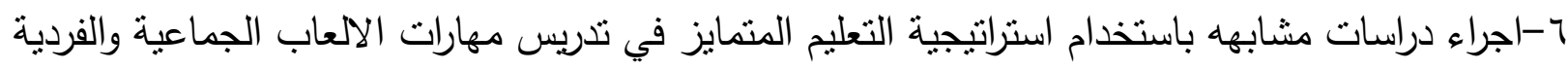
لمراحل النعليم المختلفة

المراجع

أولا : المراجع العربية : 1 - خير سليمان شواهين (ع + . ץ): التعليم المتمايز وتصميم المناهج الدراسية ـ (ط ا) ، الأردن ، عالم الكتب الحديث للنشر والتوزيع.

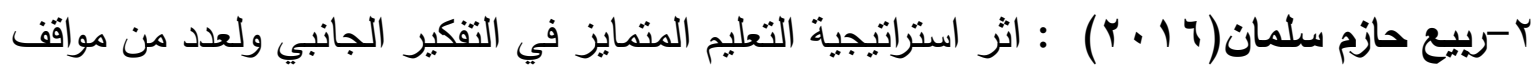
التصرف الخططي الهجومي بكرة القدم لطلبة كلية التربية البدنية وعلوم الرياضة ، بث منشور مجلة علوم الرياضة جامعة ديالى العراق العدد الأول. r- زينب على عمر(^ + . r) : غادة جلال عبد الحكيم : طرق تدريس التربية الرياضية ( الاسس النظرية والتطبيقات العملية ) دار الفكر العربي ، القاهرة ، 
ع - صبحية بنا عبدالحميد الثافعى (9 . . ץ): طرق واستراتيجيات التدريس النطبيقات في مجال الاقتصاد المنزلي، الرياض، مكتبة الرشد

0- عادل السيد جاد محمد (^ . . ץ): تأثير استخدام الاسلوب المتباين على مستوى اداء بعض المهارات الأساسية للمبنتئين فى كرة القدم ، رسالة ماجستير غير منشورة كلية التربية الرياضية ببورسعيد ، جامعة قناة

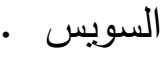

צ- ليث محمد ومحمد عيد(0 1 ب r) : أثز استراتيجية التعلم المتمايز على اكساب المهارات الهجومية في كرة اليد ، مجلة الرافدين للعلوم الرياضية ، المجلد العشرون ، العدد ستة وستون ، كلية التربية الرياضي ،

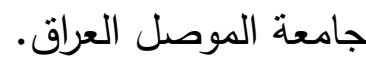

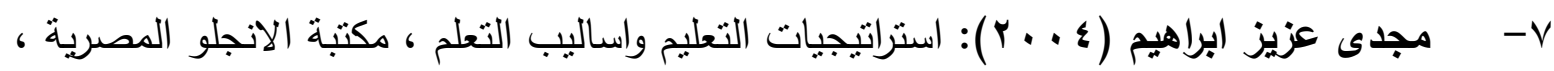

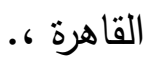

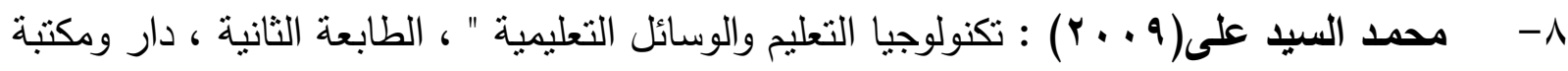

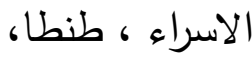

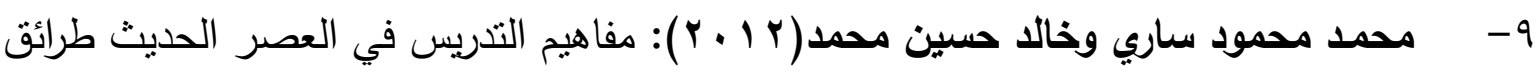
واساليب واستراتيجيات عالم الكتب الحديث ،عمان ، ل

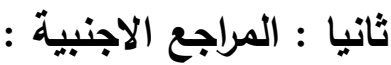

10- Duborah Stpiek( 2009). The impact of differentiated education on the achievement and motivation at the school stage, Unpublished master's thesis. University of Wisconsin-Stout

11- Patricis Koeze(2007) :The effect of differential education on the achievement of students in the preparatory stages, Delni-ncr-youth Journal of Arts, science \& commerce 
ثالثا : مواقع الانترنت :

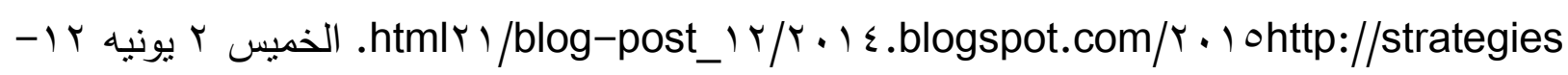
$1 \cdot:\{r P m r \cdot 11$ 